\title{
El patrocinio de Augusto y de los herederos del Princeps sobre las comunidades cívicas hispanas ${ }^{1}$
}

\author{
Enrique MelCHOR GIL \\ Universidad de Córdoba \\ ca1megie@uco.es
}

\begin{abstract}
RESUMEN
En este trabajo estudiamos las relaciones de patronazgo cívico establecidas entre los miembros de la familia imperial y diferentes ciudades hispanas, planteando la posibilidad de que algunos de estos vínculos pudieran haber surgido en época de César, en los momentos en que Octaviano buscaba alcanzar el poder o durante los primeros años del Principado. Igualmente, mostramos cómo las relaciones de patrocinio irán siendo transmitidas a los diferentes y sucesivos herederos que Augusto fue designando para sucederle: Agrippa, Cayo y Lucio Césares o Tiberio. Finalmente se analizan los motivos por los que el patronazgo imperial desaparece, siendo reemplazado por nuevos instrumentos de poder, como el culto al emperador o a Roma y Augusto, que permitieron exaltar, glorificar y garantizar la continuidad en el poder de la dinastía gobernante.
\end{abstract}

Palabras clave: Vida municipal romana. Patronazgo cívico. Honores cívicos.

\section{Patronage by Augustus and the Heirs of the Princeps in the Hispanic Civic Communities}

\begin{abstract}
This is a study on the established relationship in civic patronage between the members of the imperial family and the different Hispanic towns. We question if some of such relations have their origins in the time of Cesar, just when Octavius was trying to attain the power or during the first years of his principate. Likewise we attempt to show how the relations of patronage were successively transmitted by the different heirs appointed by Augustus to succeed him: Agrippa, Caius and Lucius Caesar, or Tiberius. Finally we analyse the reasons why the imperial patronage came to disappear, being replaced by other new implements of power, like the worship to the Emperor or to Rome and Augustus, allowing the ruling dynasty to glorify extremely their power, and so, to guarantee its continuity.
\end{abstract}

Key Words: Roman municipal life. Civic patronage. Civic honours.

\footnotetext{
1 Este trabajo ha sido realizado dentro del Subproyecto de Investigación, del Plan Nacional de $\mathrm{I}+\mathrm{D}+\mathrm{i}$, "Elites locales hispano-romanas y ejercicio del poder: su manifestación en el espacio urbano y en el territorio municipal" (Referencia: HAR2011-29108-C04-03/HIST), financiado por el Ministerio de Ciencia e Innovación, en el marco del VI Plan Nacional de Investigación Científica, Desarrollo e Innovación Tecnológica 2008-2011.
} 
Sumario: 1. El inicio del patrocinio de miembros de la familia imperial. 2. Sobre los capítulos XCVII y $C X X X$ de la Lex Coloniae Genetivae Iuliae. 3. Ulia y Emporiae. 4. Otras ciudades hispanas. 5. Sobre el declinar del patrocinio imperial. 6. El patrocinio cívico de miembros de la casa imperial en época de Tiberio. 7. Epílogo.

Entre el 27 a.C. y el 14 d.C. contamos con treinta y un testimonios epigráficos y numismáticos sobre patroni de comunidades hispanas. Catorce pertenecen al emperador o a miembros de la familia imperial, once a senadores, dos a personas cercanas a Augusto y uno a decuriones. Finalmente contamos con tres testimonios en los que no se nos ha conservado el estatus personal de quienes asumieron los patrocinios.. La abrumadora mayoría de patronos pertenecientes a la familia imperial o estrechamente vinculados a Augusto (senadores, amigos o leales funcionarios), ${ }^{2}$ muestran que las ciudades buscaron, en primer lugar, el patronazgo de personas próximas al poder, ${ }^{3}$ que pudieran defender los intereses de la comunidad ante el emperador y, si fuese necesario, ejercer su influencia personal sobre el príncipe.

\section{El inicio del patrocinio de miembros de la familia imperial}

Augusto aparece en la documentación epigráfica como patrono de los municipios de Ulia $\left(C I L \mathrm{II}^{2} / 5,486\right)$ y Emporiae $(A E 1990,662)$. La primera ciudad debió de obtener el estatuto municipal gracias a César, que le asignaría el apelativo Fidentia por su apoyo inquebrantable durante la guerra de Hispania (46-45 a.C.), mientras que la segunda pudo obtenerlo en época augustea, aunque, ya anteriormente, tras la batalla de Munda, César estableció en ella un grupo de veteranos (Liv., XXXIV 9.3). ${ }^{4} \mathrm{Am}-$ bos textos fueron atribuidos inicialmente a los nietos e hijos adoptivos de Augusto (Lucio o Cayo Césares); no obstante, actualmente se admite que los dos debieron ser dedicados al Princeps. ${ }^{5}$

Puesto que en ambas comunidades encontramos a M. Vipsanius Agrippa como patronus (CIL II ${ }^{2} / 5,488$ y IRC III, 24), así como dedicaciones a los nietos de Augusto, a los que, igualmente, se otorgó el patrocinio cívico (CIL II²/5, 487 y $A E 1990,663)$, E. Cardón interpretó que el Princeps pudo asumir el título de patrono tras la muerte

2 Entre los que se encuentran T. Statilius Taurus, patrono de Ilici (CIL II, 3556); L. Cornelius Balbus Minor, patrono de Norba Caesarina (AE 1962, 71); P. Silius Nerva, patrono de Carthago Nova (CIL II, 3414); C. Asinius Gallus patrono de la Civitas Lougeiorum (HEp 1, 1989, 458=AE 1984, 553); C. Calvisius Sabinus (cónsul del 4 a.C.), patrono de Segobriga (HEp 10, 2000, 296); Iuba II, patrono de Carthago Nova (CIL II, 3417) y escriba de Augusto M. Porcius, patrono de Segobriga (HEp 10, 2000, 301).

3 Cfr. Canali de Rossi 2001, III.

4 Sobre el estatuto de Emporiae y el momento de su obtención existe un amplio debate. Una visión actualizada y de conjunto sobre el tema puede consultarse en AMELA VALVERDE 2009, 86-90 y FASOLINI 2012, 285-291.

5 Sobre $C I L \mathrm{II}^{2} / 5,486$ (= CIL II, 1525) vid. HaRmand 1957, 160-162 y STYLOw 2008, 1056; sobre $A E$ 1990, 662 vid. Bonneville 1986, nº 6, 190 y CARDon 2004, 46-47. En el caso del epígrafe de Emporiae, seguimos la lectura propuesta en L'Année Épigraphique, que difiere de la publicada por FABRE - MAYER - RODÀ 1991, no 19, 52-53 (=IRC III, 19). 
de su yerno, el 12 a.C., debido a la corta edad de Cayo y Lucio. ${ }^{6}$ No obstante, dada la vinculación que ambas comunidades tuvieron con César, lo lógico sería plantear que el patrocinio de Augusto pudiera ser anterior y, por tanto, recibido en herencia del Divus Iulius, quien pudo haberlo obtenido previamente no sólo en ambas ciudades, sino también en las colonias mandadas deducir por él, como Tarraco. ${ }^{7}$ Otra posibilidad, ya expuesta por J. J. Seguí, sería aceptar que el Princeps fue el primer patronus de la gens Iulia, y que asumió el patrocinio sobre comunidades que habían destacado por su lealtad a su padre adoptivo o que contaban con asentamientos de veteranos pertenecientes al ejército de César, agradeciendo de esta forma su fidelitas a la gens Iulia. ${ }^{8}$ Sobre el momento en que Augusto recibió el nombramiento de patrono en ambas comunidades, podemos pensar en una fecha indeterminada tras la muerte de César, cuando, como hijo adoptivo del Divus Iulius, buscaba alcanzar el poder, aunque el patrocinio también pudo materializarse ex novo en un momento posterior a su victoria en Actium, quizás aprovechando la segunda estancia del Princeps en Hispania (27-24 a.C.). ${ }^{9}$

Durante los primeros años del Principado, y como consecuencia de las guerras civiles de finales de la República, la institución del patronato cívico debió de ser vista como potencialmente peligrosa, en el caso de que ésta fuese utilizada de forma incorrecta por posibles aspirantes al poder, lo que justificaría el intento legal de dificultar la concesión del rango de patrono, a personajes de rango senatorial, que se aprecia en el capítulo 130 de la Lex Coloniae Genetivae Iuliae. Igualmente, la importancia dada al patrocinio público permitiría explicar la destacada presencia de patroni pertenecientes a la domus Augusta -incluido el mismo emperador-o al círculo de leales al nuevo régimen que se atestigua en la epigrafía Hispana de este periodo.

Dentro de este contexto, lo lógico sería que Augusto reivindicase el establecimiento de relaciones patronales sobre las comunidades estipendiarias promocionadas a municipios por César y sobre las colonias deducidas por su padre adoptivo, al igual que desde el inicio de su carrera política había puesto especial interés en presentarse como heredero e hijo del Divus Iulius. Aunque tampoco debemos descartar que Octaviano simplemente aceptase en herencia la renovación de unas relaciones de patrocinio que previamente las comunidades cívicas habrían iniciado con César. Por otra parte, los municipios augusteos y las nuevas colonias establecidas por el Princeps también debieron cooptar a éste como patrono, siguiendo la tradición republicana que se recoge en el capítulo 97 de la Lex Coloniae Genetivae Iuliae (vid. n. 6). Desde esta

6 CARDon 2004, 42-43. Cayo y Lucio, hijos de Agripa y Julia, fueron adoptados por Augusto en el 17 a.C. Sobre su designación como herederos del Princeps y sobre los honores que recibieron en vida vid., HuRLET 1997, 113-141; SEVERY 2003, 70-71 y 164-165.

7 Recordemos que, según se establece en el capítulo 97 de la Lex Coloniae Genetivae Iuliae, el deductor colonial y sus descendientes se convertían, casi automáticamente, en patroni de la nueva colonia. Muy probablemente, el responsable de la promoción de una ciudad peregrina al rango municipal (parens municipii), así como sus descendientes, debieron también recibir el nombramiento de patronos del nuevo municipio.

8 Seguí Marco 1988, 76-77.

9 Aunque Augusto desarrolló una intensa actividad colonizadora y municipalizadora durante su tercera estancia en Hispania (15-13 a.C.), continuando la tarea iniciada durante el 27-24 a.C. (ABASCAL 2006, 68-77), pensamos que su cooptación como patrono debió ser anterior al 19-18 a.C., momento en el que su yerno y heredero, Agrippa, recibió el patrocinio sobre diversas comunidades cívicas hispanas. 
óptica, Augusto se nos presenta como cualquier otro imperator de fines de la República, que utiliza las relaciones de patrocinio y clientela sobre las ciudades como un instrumento para afirmarse en el poder.

\section{Sobre los capítulos XCVII y CXXX de la Lex Coloniae Genetivae Iuliae}

La Ley de la Colonia de Urso, deducida en el 44-43 a.C., alude en dos de sus capítulos a cómo debía realizarse el nombramiento de patrono. En el 97 se indica que serán patronos, por nombramiento del ordo decurionum y a propuesta de cualquier magistrado de la colonia -aunque sin necesidad de votación ni de quórum decurional alguno-, el deductor y el encargado de realizar las asignaciones territoriales a los colonos, así como sus hijos y descendientes. Cualquier otro aspirante a este honor deberá obtener el voto per tabellam favorable de la mayoría de los decuriones, ${ }^{10}$ estando presentes un mínimo de cincuenta. Por otra parte, en el capítulo 130 se establece que para conceder el patrocinio cívico a un senador o a su hijo tenía que realizarse una votación por escrito (per tabellam), que el candidato debía encontrarse en Italia como un particular, sin desempeñar cargo alguno, y que se debía obtener la aprobación de tres cuartas partes del total de los miembros del ordo decurionum.

Nosotros, partiendo de un senado que pudiera contar con sesenta miembros ${ }^{11} \mathrm{y}$ en función de lo señalado por los mencionados capítulos de la Lex Coloniae Genetivae Iuliae, creemos que para ser nombrado patrono en esta ciudad harían falta veintiséis votos afirmativos, sobre un quórum de cincuenta miembros del ordo, y que, en caso

10 El nombramiento de patroni debió ser una competencia exclusiva de los ordines decurionum, pues nada se indica ni en la Lex Ursonensis, ni en ninguna otra de época posterior, de la participación del populus en la cooptación de patronos. En algunas tablas de hospitalidad y de patronato se menciona conjuntamente al senatus populusque como artífices de la cooptación de un patrono (CIL II, 3695) o como una de las partes que aceptaron establecer un hospitium con un destacado personaje de la sociedad romana (CIL II, 1343; CILA II, 1053); no obstante, en los casos hispanos conocidos se trata de comunidades estipendiarias que pudieron utilizar expresiones tomadas del vocabulario jurídico-institucional romano para señalar que el conjunto de la civitas se veía afectada y asumía esta decisión. Pese a lo comentado, en un epígrafe de Corfinium podemos leer splendidissimus ordo consentiente populo tabulas patrocinales aheneas liberisque eius offerri (CIL IX, 3160), lo que podría indicarnos que en las ciudades de estatuto privilegiado el nombramiento de patrono, previamente aprobado por el senado local, debió ser presentado al populus en una contio para que, simplemente, lo ratificase mediante aclamación. En un epígrafe de la colonia de Banasa, del 75 d.C., nos encontramos con que los coloni coloniae Iulia Valentiae Banasae (...) patronum cooptaverunt (AE 1941, 79), mientras que en otro, del 162 d.C., vuelven a aparecer los habitantes de la ciudad cooptando a un patrono, aunque en este caso se señala por decreto de los decuriones: Aurelii Banasitani ex decreto splendidissimi ordinis... patronum sibi (...) cooptaverunt $(A E$ 1948, 115). Suponemos que en el primero de los testimonios banasitanos mencionados se omitió la expresión ex decreto ordinis por hace alusión a un procedimiento que, sin duda, fue necesario para conceder el patrocinio sobre cualquier comunidad cívica, como señalan las leyes municipales y como puede constatarse en una inscripción de Agbia, en la que se señala el nombramiento de un patrono ex consensu decurionum omnium (CIL VIII, 1548). Por lo comentado, la mención a los Aurelii Banasitani, en el epígrafe AE 1948, 115, o a los Baetulonenses, en otra inscripción hispana (IRC I, 139 = FABRE - MAYER - RODÀ 1984), como responsables del nombramiento del patrono, sólo indica, oficialmente, que el colectivo ciudadano asumía una decisión que previamente había aprobado el ordo decurionum. Sobre el tema vid., Harmand 1957, 329-332; RAMPAZZO 2007, 191-207.

11 Sobre el número de sesenta decuriones con los que pudo contar Urso al crearse la colonia vid., MeLCHOR 2013, 221-223. 
de ser senador, el aspirante a patrono necesitaría cuarenta y cinco votos afirmativos de un total de sesenta posibles. Para L. Harmand, el capítulo 97 es de inspiración cesariana y por ello facilita la elección como patrono a los fundadores de colonias o a los encargados de asignar las tierras a los colonos, así como a sus descendientes, o, dicho de otra forma, a César, si la muerte no le hubiera llegado tan pronto, y a sus principales colaboradores. Igualmente, piensa que el capítulo 130 sería un añadido de Marco Antonio realizado en el 44 a.C., tras el asesinato del dictador, y buscaría dificultar a sus adversarios políticos el control sobre cualquier colonia cesariana, en especial a Bruto, Casio y Sexto Pompeyo. ${ }^{12}$ Diferentes trabajos han destacado la escasa implicación de las clientelas cívicas en la guerra civil entre César y Pompeyo, al menos en Hispania e Italia, ${ }^{13}$ lo que nos lleva a pensar que las disposiciones legales recogidas en el capítulo 130 de la Lex Coloniae Genetivae Iuliae no debieron de estar condicionadas por un inminente enfrentamiento con los tiranicidas y que, por tanto, no fueron destinadas a evitar que miembros de estas facciones pudieran obtener el nombramiento de patronos cívicos.

\begin{tabular}{|c|c|c|}
\hline & \multicolumn{2}{|c|}{ Lex Colonia Genetivae Iuliae } \\
\hline Rango del patrono: & No Senador (cap. XCVII) & Senador (cap. $C X X X$ ) \\
\hline Quórum necesario & $\begin{array}{l}\text { Mayoría sobre un mínimo de } 50 \\
\text { decuriones }\end{array}$ & $\begin{array}{l}\text { No se establece pero se exige el voto } \\
\text { afirmativo de tres cuartas partes de los } \\
\text { decuriones }\end{array}$ \\
\hline \multirow[t]{2}{*}{$\begin{array}{l}\text { Número de votos afirmativos } \\
\text { necesarios para ser nombrado } \\
\text { patrono }\end{array}$} & 26 & $\begin{array}{l}\text { Voto afirmativo de tres cuartas partes } \\
\text { de los miembros del ordo: } \mathbf{4 5} \text { sobre un } \\
\text { modelo de curia con } 60 \text { miembros }\end{array}$ \\
\hline & \multicolumn{2}{|c|}{ Lex Irnitana (cap. $L X I)$} \\
\hline Rango del patrono: & \multicolumn{2}{|c|}{ Indistinto (senador o no senador) } \\
\hline Quórum necesario & \multicolumn{2}{|c|}{$2 / 3$ de los decuriones } \\
\hline $\begin{array}{l}\text { Número de votos afirmativos } \\
\text { necesarios para ser nombrado } \\
\text { patrono }\end{array}$ & \multicolumn{2}{|c|}{$\begin{array}{l}\text { Mayoría de los miembros del ordo, estando presentes al menos } 2 / 3 \text { de } \\
\text { los decuriones: } \\
\mathbf{2 1} \text { sobre un modelo de curia con } 60 \text { miembros }\end{array}$} \\
\hline
\end{tabular}

Fig. 1. Modelo teórico sobre el número de votos que pudieron ser necesarios para ser nombrado patrono cívico en Urso e Irni, según los datos contenidos en su legislación y utilizando (a modo de ejemplo) un plenus ordo de 60 decuriones.

Pese a lo comentado, el número exigido de cuarenta y cinco votos afirmativos parece destinado a dificultar el acceso al patronato de miembros del ordo senatorius, dado que un caballero o decurión sólo necesitaba veintiséis. El carácter restrictivo de la norma del estatuto de Urso se vuelve a poner de manifiesto si aplicamos a un colectivo de sesenta decuriones lo establecido en el capítulo 61 de la Lex Irnitana sobre la elección de patroni. Según esta ley, para obtener el patrocinio sobre una comunidad cívica se necesitaría el voto positivo de la mayoría de los decuriones, estando presentes un mínimo de dos tercios de los miembros del ordo, o, lo que es lo mismo, veintiún votos (vid. Fig. 1). Evidentemente, en época flavia las exigencias se habían

12 HaRmand 1957, 142-145.

13 Eilers 2002, 96-97; Pina Polo, 2008; Nicols 2014, 47 y 62-65. 
relajado, en un momento en el que el patrocinio sobre comunidades había dejado de ser visto por el poder central como peligroso, dado que desde época imperial se consideraba una distinción honorífica frecuentemente conferida a personas que podían actuar en beneficio de las ciudades por su cercanía y fidelidad al emperador, así como por mantener vínculos de amicitia con éste. ${ }^{14}$ Pero esta valoración del patrono cívico no como un posible competidor, sino como un colaborador del régimen imperial, debió de implantarse, poco a poco, durante el largo gobierno de Augusto, conforme el nuevo régimen se dotó de estabilidad, de instituciones firmes y de herederos.

Quizás, las restricciones impuestas en el capítulo 130 del estatuto de Urso puedan vincularse a disposiciones augusteas que intentarían dar mayor estabilidad al nuevo régimen surgido tras Actium, limitando la extensión de las clientelas cívicas de las familias senatoriales, ${ }^{15}$ salvo que éstas se encontrasen cercanas al poder y contaran con su apoyo institucional. De forma paralela, se buscaría resaltar la figura del Princeps, primero como patrono de diferentes ciudades que le ofrecieron este título y de las colonias deducidas por él o por su padre adoptivo, ${ }^{16} \mathrm{y}$, posteriormente, como pater patriae.

En el capítulo 130 de la Lex Coloniae Genetivae Iuliae se señala que un senador sólo podría ser nombrado patrono si se encontraba como particular en Italia. Para J. Nicols esta disposición sería de época cesariana, ya que con anterioridad, en la Lex Iulia de pecuniis repetundis (59 a.C.), se establecía la prohibición de que los gobernadores recibieran honores de las ciudades durante su mandato. ${ }^{17}$ Posteriormente, dado que la norma no se cumplió, ni durante el triunvirato, ni en los primeros años del Principado, Augusto, en el 11-12 d.C., ordenó que las comunidades peregrinas no concedieran ningún honor a los magistrados mientras éstos tuvieran alguna responsabilidad sobre ellos y hasta pasados sesenta días de su partida de la provincia ${ }^{18}$ (Dio Cass., 56.25.6). Por tanto, la nueva disposición legal prohibía nombrar patroni a los gobernadores provinciales durante el ejercicio del cargo. De esta forma se intentaba evitar que un gobernador corrupto pudiera protegerse de una futura acusación de repetundis imponiendo patrocinios a las principales ciudades de la provincia administrada, dado que la tradición romana consideraba inmoral que los clientes llevaran a sus patronos a juicio. ${ }^{19}$ Teniendo presente tanto la ineficacia de la norma dada por César, en el 59 a.C., como la especificidad de la medida impuesta por Augusto (Dio Cass., 56.25.6), que concuerda plenamente con lo estipulado en el capítulo $130 \mathrm{del}$ estatuto de Urso, así como otras cuestiones formales, de redacción y contenido, ya

14 Cfr. Nicols 1978, 429-430; Duthoy 1984-86, 121; Lintott 1999, 170-171.

15 Como señaló R. Syme 1989, 506-507, Augusto, en un principio, buscó limitar las clientelas de las grandes familias senatoriales, dificultando la obtención de patronatos cívicos o provinciales.

16 Cfr. Harmand 1957, 157-159 y SEgenni 2009, 264-265.

17 Nicols 1979, 246-247; ID. 2014, 211-213. M. H. CrAwFord (ed.), 1996, vol. II, 771-772, admite que esta norma formó parte de la Lex Iulia de pecuniis repetundis, aunque señala que el jurista Paulo, al recoger este fragmento de la ley, pudo actualizar el lenguaje utilizando términos de época altoimperial, como curia y praeses.

18 Una norma similar existiría para las comunidades con estatuto privilegiado, como se aprecia en el capítulo 130 de la Lex Coloniae Genetivae Iuliae.

19 Nicols 1979, 247-248; ID. 1990, 85-86 y 92; ID. 2014, 213-218. 
apuntadas por X. D'Ors, ${ }^{20}$ pensamos, como sugirió M. H. Crawford, y como han planteado recientemente F. Beltrán, F. Pina y J. Nicols, ${ }^{21}$ que dicho capítulo de la Lex Coloniae Genetivae Iuliae debió de ser redactado durante los últimos años de gobierno del Princeps y que está integrando en la ley colonial similares disposiciones a las que éste había establecido, en el 11-12 d.C., para las comunidades no privilegiadas. En apoyo de nuestro planteamiento, hemos de tener presente que el proceso de fijación del texto definitivo de la ley colonial de Urso abarcó un amplio periodo que discurrió entre el 45 a.C. y el 24 d.C., ya que en ella se contienen disposiciones diseñadas por César, junto con otras influenciadas por la legislación augustea, ${ }^{22}$ mientras que no se contemplan otras de obligado cumplimiento que fueron aprobadas en época tiberiana, ${ }^{23}$ como la Lex Visellia, del 24 d.C., que impedía a los libertos acceder al rango decurional.

\section{Ulia y Emporiae}

En Ulia, junto al señalado patronato de Augusto, contamos con otros pedestales ecuestres que conceden el mismo honor a Agripa $\left(C I L \mathrm{II}^{2} / 5,488\right)$ Lucio César $(C I L$ $\left.\mathrm{II}^{2} / 5,487\right)$ y Tiberio $\left(C I L \mathrm{II}^{2} / 5,490\right) .{ }^{24}$ El patronato de Agrippa, así como el epígrafe que le dedicaron en la ciudad, podría datarse en el 19-18 a.C., en el marco de un viaje al sur peninsular que debió de realizar tras finalizar las guerras cántabras (19 a.C.). ${ }^{25}$ Lucio pudo ser cooptado como patrono tras la muerte de su padre, aunque dada la juventud del príncipe en el 12 a.C., E. Cardón ha planteado, creemos que acertadamente, que su nombramiento tendría lugar a partir del 2 a.C. ${ }^{26}$ Tiberio fue honrado como

20 D'Ors 1997, 82-84, señaló la existencia de diferencias formales, de redacción y contenido entre los capítulos 97 y 130 de la lex, que apuntan a que ambos fueron redactados en momentos diferentes, siendo más antiguo el 97. Entre ellas debemos destacar que la multa impuesta al infractor en el capítulo 97 es sólo de cinco mil sestercios, mientras que la establecida para quien incumpla lo establecido en el capítulo 130 alcanza los cien mil. Esta alta cantidad no vuelve a aparecer en todo el estatuto ursonense, donde las mayores multas sólo alcanzan los veinte mil sestercios. Para encontrar una cifra similar es necesario avanzar en el tiempo hasta época flavia, pues en el capítulo 96 de la Lex Irnitana se impone una sanción de esta cuantía a quien contravenga, cometa fraude o impida la aplicación de la ley municipal.

21 Crawford (ed.), vol. I, 452; Beltrán - Pina 2013, 60; Nicols 2014, 87, n. 11 y 227, n. 53.

22 Así, los capítulos 125 a 128 de la Lex Coloniae Genetivae Iuliae adaptan su contenido a la Lex Iulia Theatralis del 20-17 a.C.

23 Caballos Rufino 2006, 392-411. Recordemos, además, que para A. U. StYlow 1997, 43, la Ley de la colonia Genetiva Iulia está paleográficamente mucho más cerca de los bronces hispanos de época de Tiberio, $\mathrm{y}$, por tanto, podría haberse grabado en el segundo cuarto del siglo I d.C.

24 El conjunto epigráfico en honor de la familia imperial se completa con otras inscripciones dedicadas a Cayo o Lucio Césares $\left(C I L \mathrm{II}^{2} / 5,491\right)$ y a Agripa Póstumo $\left(C I L \mathrm{II}^{2} / 5,489\right)$. Igualmente contamos en la ciudad con un Prefecto de Cayo César (CIL II $2 / 5,495)$. Sobre las inscripciones ulienses vid., AbASCAL 1996, 55-56.

25 La ausencia de mención a la tribunicia potestad permitiría fechar la inscripción en la primera mitad del 18 a.C., al igual que ocurre con el epígrafe IRC III, 24, de Emporiae. Nosotros pensamos que la segunda estancia de Agripa en la Península Ibérica, tras su boda con la hija de Augusto (21 a.C.), pudo ser el momento adecuado para recibir el patronato de diferentes ciudades hispanas. Sobre el posible viaje de Agripa al sur peninsular vid., RoDDAZ 1984, 413.

26 Año en el que Lucio tomó la toga viril, fue presentado ante el senado y designado princeps iuventutis. El joven príncipe murió en el 2 d.C. CARDON 2004, 46. 
patronus de Ulia antes de su adopción por Augusto, en el 4 d.C. Según E. Cardón este título se le pudo conceder a partir del 26-25 a.C., cuando participó como tribuno militar, a las órdenes de Augusto, en las guerras cántabras; ${ }^{27}$ no obstante, creemos que las posibilidades de ser cooptado como patrono debieron de aumentar notablemente tras la muerte de Agripa y su matrimonio con Julia, en el 11 a.C.

En Emporiae, además del Princeps, fueron patroni Agripa (IRC III, 24) y Cayo o Lucio Césares (AE 1990, 663). El patrocinio de Agripa, así como el epígrafe que le dedicaron en esta comunidad podría datarse, por la ausencia de mención a la potestad tribunicia, en el 19-18 a.C., coincidiendo con su estancia en Hispania para poner fin a las guerras cántabras. Los escasos fragmentos conservados de una placa de mármol emporitana nos impiden conocer si el otro patrono de la familia imperial atestiguado en la ciudad fue Cayo o Lucio César. En caso de hacer referencia al primero, su patrocinio debería fecharse a partir del 5 a.C. ${ }^{28}$ mientras que, si se tratara del segundo, el nombramiento de patrono se le concedería al nieto de Augusto desde el 2 a.C., al igual que ocurrió en Ulia.

Como parece mostrar la documentación epigráfica, tanto Emporiae como Ulia buscarían mostrar su lealtad a la domus imperatoria ofreciendo el patronato a Augusto y a diferentes miembros de la casa imperial. Entrando en la clientela del Princeps, ambas ciudades pudieron formalizar o dar oficialidad a unos vínculos afectivos con la familia de Augusto que debieron de haber comenzado a establecerse desde la época de César. Sin duda, el patrocinio cívico contribuiría a reforzar y a mantener unos lazos forjados durante las guerras civiles, del 49-45 a.C., entre cesarianos y pompeyanos.

\section{Otras ciudades hispanas}

La concesión del patronato y su aceptación por parte del Princeps muestra una estrecha y antigua vinculación de Ulia y Emporiae con la gens Iulia que, como hemos señalado, pudo formalizarse con César o Augusto, siendo continuada de forma hereditaria por Agrippa, Cayo y Lucio Césares. No obstante, esta relación de patrocinio de la familia imperial también debió de darse en otras ciudades hispanas que recibieron un estatuto privilegiado de César o de Augusto; así como en colonias establecidas por cualquiera de ambos personajes, puesto que al asumir el papel de deductor coloniae o de parens municipii, tanto el Divus Iulius como el Princeps y, por tanto, sus descendientes tendrían derecho a ser nombrados patroni. La hereditariedad de los lazos de patronato, ${ }^{29}$ el interés del emperador por convertirse en el protector de todos

27 Cardon 2004, 41-42. La onomástica de Tiberio (Tiberius Claudius Nero) impide datar el epígrafe después del 4 d.C. Igualmente, la autora señala que la inscripción debe ser anterior al 5 a.C., ya que desde el verano del 6 a.C. hasta agosto-septiembre del 2 d.C. el futuro emperador estuvo exiliado en Rodas. Cfr. HuRLET 1997, $105-113$.

28 Año en el que Cayo tomó la toga viril, fue presentado ante el senado y designado princeps iuventutis. El joven príncipe murió en el 4 d.C. CARDON 2004, 46.

29 Frente a las teorías imperantes entre los principales investigadores del tema, hace una década C. EILERS 2002, 61-83, negó el carácter estrictamente hereditario de los patrocinios cívicos. Nosotros pensamos que los lazos de patronato se heredaban, como queda reflejado en numerosas tabulae patronatus, donde se indica claramente que las relaciones clientelares y de patrocinio pasarán a los hijos y descendientes de los firmantes 
los habitantes del Imperio, que le llevará a aceptar el título de pater patriae (2 a.C.), o la existencia de varios testimonios de patrocinios cívicos, así como de proyectos edilicios, asumidos por diferentes miembros de la domus Augusta y conservados en Carthago Nova ${ }^{30}$ o en Augusta Emerita, ${ }^{31}$ parecen apuntar en la dirección señalada, independientemente de que, en otras ocasiones, sólo nos quede registro epigráfico del patronazgo individual de Agripa, de los nietos de Augusto o de Tiberio (vid. Fig. 2). Por lo señalado, la misma vinculación patronal de la familia imperial pudo darse en otras ciudades hispanas, en concreto con la colonia establecida por Augusto en Salaria (CIL II, 5093), así como con el municipio cesariano de Gades (RPC, 77-84) 32 y con el creado por César o Augusto en Italica (CIL II, 1113). No obstante, al contar con sólo un testimonio de patrocinio en cada una de estas comunidades, debemos plantear esta hipótesis con precaución. Con similar cautela, podríamos sugerir que determinados testimonios de patrocinios cívicos concedidos a Cayo o Lucio Césares en otras ciudades del Occidente romano, que recibieron el estatuto de colonia (Rusellae, Pisa, Nemausus) u otros beneficia de Augusto (Lugdunum), puedan estar encubriendo una relación de patronato heredada del mismo Princeps. ${ }^{33}$

del pacto (Baetulonenses ex Hispania citerio/re hospitium fecerunt / cum Q(uinto) Licinio Silvano Graniano / eumque liberos posterosque / eius sibi liberis posterisque / suis patronum cooptaverunt, IRC I, 139=AE 1936, 66 de Baetulo; en CIL VI, 1684 se nombra patrono al honrado y a sus descendientes). Incluso, en alguna de ellas se menciona que ancestros ilustres del honrado habían desempeñado la misma función (en $A E$ 1937, 119 se indica que C. Sallius Sofronius Pompeianus, su bisabuelo y su padre fueron patronos de Amiternum). Igualmente, numerosos epígrafes honoríficos señalan claramente que el patronato fue recibido en herencia (tabulas patrocinales aheneas liberisq(ue) eius offerri censuerunt, CIL IX, 3160 de Corfinium) y en el Oriente griego lo confirman diferentes inscripciones recogidas por F. CANALI DE RosSI 2001, $\mathrm{n}^{\circ} 17,42,72$, $73,76,112,120$ y 123). Los textos literarios señalan la misma idea: así, el patronato de la familia de Claudio Marcelo sobre Siracusa, iniciado a fines del siglo III a.C., pervivía en época de Cicerón (Verr., 2.3.8 y 4.41.8990); o los hijos de Pompeyo pudieron reclamar el apoyo de diversas ciudades de la Ulterior invocando los lazos de patronato que éstas habían establecido con su padre (Bell. Hisp. 1.1). En la misma línea de nuestras argumentaciones, y respondiendo a las teorías de C. Eilers, puede consultarse el trabajo de D. BLoy 2012, 179-181. Numerosos testimonios de patronato hereditario están, igualmente, constatados en los siglos IV y V d.C. y han sido analizados por F. CHAUsSON 2004, 71-120.

30 Frente a las teorías que la consideraban una colonia cesariana, Carthago Nova debió recibir el estatuto colonial de Pompeyo (hacia el 54 a.C.), como planteó J. M. ABASCAL 2002, 21-44, y parecen confirmar diferentes inscripciones que aluden al comienzo de una reforma del recinto amurallado de la ciudad, a la construcción de un acueducto y fuentes públicas o a la donación de un templo a Esculapio. Todas estas obras, destinadas a la renovación urbana de la nueva colonia, se datarían entre el 54 y el 49 a.C., coincidiendo con el periodo de asignación de las provincias Hispanas a Pompeyo. Sobre ellas vid., DíAz ARIÑo 2008a, 227230; ID. 2008b 255-263; RAMAllo - Murcia 2010, 249-258. Pese a lo señalado, tras la victoria de Munda, la colonia cambió su nombre, pasando a denominarse colonia Urbs Iulia Nova Carthago. Como señaló J. M. ABASCAL 2002, 32-33, la vinculación de la ciudad a César y a Octaviano debió comenzar a fraguarse a partir del 45 a.C., durante la estancia de ambos en ella, cuando viajaban de Gades a Tarraco (Nic. Dam., de vita Aug. 10.11). Desde este momento las aristocracias locales buscaron aproximarse a la familia imperial o a amigos y colaboradores cercanos al Princeps.

31 Colonia augustea, como defendió J. C. Saquete 1996, 23-39, frente a A. Ma ${ }^{\text {a }}$ CANTo 1989, 149-205 e ID. 1990, 289-297, que planteó una fundación previa cesariana.

$32 R P C=$ BURNETT - AMANDRY - RIPOLLÈs 1992.

33 Rusellae $(A E$ 1980, $448=A E$ 1998, 445 y $A E$ 1980, $449=A E$ 1998, 444); colonia Obsequens Iulia Pisana (CIL XI, 1420 y 1421); Nemausus (CIL XII, 3155); Lugdunum (AE 1962, 16). Sobre éstos y otros patrocinios cívicos asumidos por los nietos de Augusto en ciudades de Italia y del Occidente romano vid., Cenerini 2010, 120 y Segenni 2011, 58-60. En algún caso, como el de la colonia Alba Fucens tenemos 


\begin{tabular}{|c|c|c|c|c|c|}
\hline & $\begin{array}{l}\text { C. IULIUS } \\
\text { CAESAR }\end{array}$ & $\begin{array}{l}\text { IMPERATOR } \\
\text { CAESAR } \\
\text { AUGUSTUS }\end{array}$ & $\begin{array}{l}\text { M. VIPSANIUS } \\
\text { AGRIPPA }\end{array}$ & $\begin{array}{l}\text { C. о L. CAESAR } \\
\text { AUGUSTI F. }\end{array}$ & $\begin{array}{l}\text { TIBERIUS } \\
\text { CLAUDIUS } \\
\text { NERO }\end{array}$ \\
\hline ULIA & $\begin{array}{l}\text { Municipio } \\
\text { cesariano }\end{array}$ & $\begin{array}{l}\text { PATRONO (CIL } \\
\mathrm{II}^{2} / 5,486, \text { base de } \\
\text { estatua ecuestre) }\end{array}$ & $\begin{array}{l}\text { PATRONO (CIL } \\
\mathrm{II}^{2} / 5,488, \text { base de } \\
\text { estatua ecuestre) }\end{array}$ & $\begin{array}{l}\text { LUCIO CÉSAR } \\
\text { PATRONO (CIL } \\
\text { II }^{2} / 5,487, \text { base de } \\
\text { estatua ecuestre })\end{array}$ & $\begin{array}{l}\text { PATRONO } \\
\left(C I L \mathrm{II}^{2} / 5,490,\right. \\
\text { base de estatua } \\
\text { ecuestre })\end{array}$ \\
\hline EMPORIAE & $\begin{array}{l}\text { Asentamiento } \\
\text { de veteranos }\end{array}$ & $\begin{array}{l}\text { PATRONO (AE } \\
1990,662 \text { placa } \\
\text { honorífica) }\end{array}$ & $\begin{array}{l}\text { PATRONO (IRC III, } \\
24 \text { placa honorífica) }\end{array}$ & $\begin{array}{l}\text { C. o L. CÉSAR } \\
\text { PATRONO (AE } \\
\text { 1990, } 663 \text { placa } \\
\text { honorífica) }\end{array}$ & \\
\hline $\begin{array}{l}\text { CARTHAGO } \\
\text { NOVA }\end{array}$ & \begin{tabular}{|l|} 
Nuevo \\
nombre: \\
Colonia Urbs \\
Iulia Nova \\
Carthago
\end{tabular} & & $\begin{array}{l}\text { PATRONO (AE } \\
\text { 1979, 366 pedestal } \\
\text { honorífico) }\end{array}$ & $\begin{array}{l}\text { Financiación del } \\
\text { teatro }\end{array}$ & $\begin{array}{l}\text { PATRONO (CIL } \\
\text { II, } 5930 \text { pedestal } \\
\text { honorífico) }\end{array}$ \\
\hline $\begin{array}{l}\text { AUGUSTA } \\
\text { EMERITA }\end{array}$ & $\begin{array}{l}\text { ¿Praesidium } \\
\text { cesariano? }\end{array}$ & Colonia augustea & $\begin{array}{l}\text { Segunda deductio } \\
\text { colonial; financiación } \\
\text { del teatro }\end{array}$ & $\begin{array}{l}\text { CAYO Y LUCIO } \\
\text { CÉSARES } \\
\text { PATRONOS (HEp } \\
18,2009,40 \text { y } 41 \\
\text { placa del balteus } \\
\text { del teatro) }\end{array}$ & \\
\hline GADES & $\begin{array}{l}\text { Municipio } \\
\text { cesariano }\end{array}$ & & $\begin{array}{l}\text { PATRONO (RPC } \\
\text { I, 77-84 emisiones } \\
\text { monetales cívicas) } \\
\end{array}$ & & \\
\hline ITALICA & & $\begin{array}{l}\text { Municipio } \\
\text { augusteo }\end{array}$ & & & $\begin{array}{l}\text { PATRONO (CIL } \\
\text { II, } 1113 \text { placa } \\
\text { honorífica) }\end{array}$ \\
\hline SALARIA & & Colonia augustea & & $\begin{array}{l}\text { C. o L. CÉSAR } \\
\text { PATRONO (CIL } \\
\text { II, 5093, pedestal } \\
\text { honorífico) }\end{array}$ & \\
\hline
\end{tabular}

Fig. 2. Ciudades hispanas que recibieron un estatuto jurídico privilegiado en época cesariano-augustea o que contaron con patrocinios de miembros de la familia imperial en época de Augusto.

En Carthago Nova tenemos atestiguado el patrocinio cívico de Agripa ( $A E$ 1979, 366) y de Tiberio (CIL II, 5930). El pedestal dedicado al yerno de Augusto ha sido datado entre el 18 y el 12 a.C., ${ }^{34}$ aunque, como en otros casos ya comentados, su patrocinio sobre la ciudad debería fecharse en el 19-18 a.C. El pedestal erigido a Tiberio, antes de su adopción por el Princeps, así como su nombramiento de patrono de la ciudad debería fecharse entre el 12 y el 6 a.C., como hemos propuesto para otro testimonio similar procedente de Ulia. La documentación conservada nos muestra una intensa vinculación de la ciudad con la familia imperial y con colaboradores directos del Princeps, como sería el caso de los patroni P. Silius Nerva (CIL II, 3414) y Iuba II (CIL II, 3417). Diferentes emisiones monetales atestiguan el ofrecimiento del duunvirato quinquenal en

atestiguados los patrocinios cívicos de Julio César (AE 1964, 7), Lucio César (CIL IX, 3914) y, probablemente, de Agripa (CIL IX, 3913).

34 M. Косн 1979, 205-214, fechó el epígrafe entre el 18 y el 8 a.C.; J. M. AbasCAL - S. Ramallo 1997, nº 44, 175-177, datan la inscripción antes del 12 a.C. 
Carthago Nova a Augusto, Agripa, Tiberio, a los hijos de Germánico (Nerón y Druso) y a Calígula; ${ }^{35}$ mientras que el programa epigráfico del teatro parece indicar que la obra y su ornamentación escultórica fue financiada por los nietos de Augusto, quienes, pese a la falta de testimonios conservados, debieron heredar el patrocinio sobre la colonia de su padre, lo que explicaría su implicación en el programa de renovación urbana de Carthago Nova. Un par de inscripciones monumentales colocadas sobre los aditi de acceso a la orchestra, con los nombres de Cayo y Lucio Césares (HEp 5, 581; HEp $7,415)$, así como, el ya mencionado patronato que ejerció Agripa sobre esta ciudad, hacen pensar claramente en una intervención directa de la familia imperial. Dado que Agripa murió en el 12 a.C. y que el edificio fue inaugurado antes de la muerte de Lucio César, ${ }^{36} \mathrm{~S}$. Ramallo y E. Ruiz han defendido que el edificio teatral pudo ser financiado por Cayo y Lucio, señalando que éstos incluso pudieron haber asumido y llevado a término un compromiso adquirido anteriormente por su padre. ${ }^{37}$ La monumentalidad de las inscripciones y su lugar de emplazamiento en los tribunalia, sobre los aditi de acceso a la orchestra ${ }^{38}$ parecen refrendar esta hipótesis, que vuelve a ser confirmada por la información grabada sobre un ara dedicada por Lucio Junio Paeto en nombre de Cayo César (HEp 5, 1985, 582). En ella se indicaría que esta pieza y el conjunto de altares neoáticos del teatro habrían sido donados por el nieto de Augusto. ${ }^{39}$

35 Llorens Forcada 1994, 31-34. J. J. Seguí 1996, 1559, propuso que en Carthago Nova el ofrecimiento del duunvirato quinquenal pudo preceder al nombramiento como patroni de diferentes miembros de la familia imperial o de determinados personajes que fueron honrados con esta magistratura. No obstante, la datación de las diferentes emisiones monetales que conmemoran el ofrecimiento de la quinquenalidad como un honor parece apuntar a que, en ocasiones, esta magistratura pudo concederse a personas que previamente habían sido nombrados patronos, como podría deducirse si cruzamos las posibles fechas de recepción de ambos honores en los casos conocidos de Agripa (patronato: 19-18 a.C.; emisión X del 14 a.C. según ABASCAL 2002, 31-32) y de Tiberio (patronato: 12-6 a.C.; emisión XI del 9 a.C. según ABASCAL 2002, 31-32). En el caso de Iuba II no podemos cruzar ambas fechas, ya que la inscripción que conmemora su patrocinio sobre la ciudad ha sido datada utilizando como referencia el posible año de emisión de la serie monetal XIII de Carthago Nova (el 2 d.C.). Pese a lo señalado, y mientras no tengamos otras testimonios que lo confirmen, no somos partidarios de interpretar que el ofrecimiento de una magistratura cívica a un miembro de la domus imperatoria pudiese implicar una futura cooptación de éste como patrono, ni tampoco ser una consecuencia derivada del previo establecimiento de unas relaciones de patrocinio. La existencia de praefecti de los emperadores y príncipes en diferentes ciudades no nos autoriza a interpretar que dichos miembros de la familia imperial también fueron nombrados patronos, pues, mientras que el patronato imperial cívico desaparece con Tiberio, numerosos emperadores y príncipes continuaron asumiendo magistraturas cívicas honoríficas durante los siglos I y II d.C., como podemos constatar en Italia gracias a M. C. Spadoni 2004, tabla 1 Praefecti Caesaris/Imperatoris, 268-269.

36 El texto de la inscripción $H E p$ 7, 1997, 415, dedicada a Lucio César y colocada sobre el aditus oriental que daba acceso a la orchestra, nos muestra que ésta fue emplazada en su posición original antes de la muerte del joven príncipe, acaecida en el 2 d.C. Por otra parte, un ara dedicada en el teatro (HEp 5, 1995, 582), en nombre de Cayo César, que aparece como princeps iuventutis (5 a.C.) y consul designatus, nos revela que ésta fue erigida antes de su acceso al consulado, el 1 d.C. La información contenida en ambos epígrafes permitió a S. RAmallo - E. Ruiz 1998, 138, establecer la fecha de inauguración del edificio entre el 5 a.C. y el 1 d. C.

37 Ramallo - Ruiz 1998, 125-140.

38 Este destacado lugar era donde se colocaban las inscripciones de los evergetas que hubiesen financiado la construcción del edificio. Los tribunalia quedaban reservados a los organizadores de los juegos escénicos y, por tanto, se convertían en el centro de atención visual durante la inauguración de cualquier representación teatral dada por magistrados o evergetas, quienes, según P. ZANKER 1992, 375, "aparecían ante el público como estatuas vivas instaladas sobre arcos honoríficos".

39 Abascal - Ramallo 1997, 119; Ramallo - Ruiz 1998, 140. 
La implicación de los césares en la construcción del edificio teatral de Carthago Nova encuentra su paralelo en el teatro de Augusta Emerita, mandado edificar por su padre, y debe relacionarse con el importante valor simbólico y cívico que se le dio a los teatros desde época augustea. Los edificios teatrales se convirtieron desde inicios del Principado en lugar de encuentro entre los símbolos del poder estatal y los administrados. Sus ciclos estatuarios dedicados a la domus imperatoria y a las divinidades tutelares del estado así como los espacios sagrados dedicados al naciente culto imperial, que fueron levantados dentro de los teatros, ayudaron a configurar un espacio conmemorativo y sacralizado donde las comunidades cívicas se reunían periódicamente para venerar al emperador y mostrar su lealtad a la casa imperial que los gobernaba. De esta forma, los teatros se convirtieron en eficaces instrumentos de propaganda política del Principado, destinados a glorificar a la dinastía gobernante ante los administrados y a transmitir una serie de ideas de paz, prosperidad (Aurea Aetas) o de divinidad del poder, que ayudasen a garantizar la continuidad dinástica del nuevo régimen. ${ }^{40}$ Dentro de esta visión del teatro, como lugar de exaltación de la dinastía gobernante, el programa epigráfico del teatro de Carthago Nova presenta a Cayo y a Lucio no solo como herederos legítimos del Princeps, sino también como evergetas y protectores de la ciudad, que pudieron haber heredado el patronato de Agripa.

En Augusta Emerita, A. U. Stylow y A. Ventura han propuesto una nueva lectura de dos inscripciones, grabadas sobre sendas piezas del balteus de la prohedria del teatro, que aludirían a una reserva de asientos para Cayo y Lucio Césares como patro$n i$ de la colonia (HEp 18, 2009, 40 y 41); ${ }^{41}$ título que debieron heredar de su padre $M$. Vipsanius Agrippa, quien realizó, en el 19-18 a.C. una segunda deductio en la colonia con veteranos procedentes de las guerras cántabras. Este asentamiento de nuevos colonos, junto con su preocupación de dotar a la ciudad de nuevos edificios, como el teatro, ${ }^{42} \mathrm{o}$ su aparición en un relieve localizado en la zona de Pancaliente, donde es representado sacrificando un toro, ${ }^{43}$ han hecho que autores como J.-M. Roddaz lo consideren patrono de Emerita, aunque ningún epígrafe conservado lo confirme. ${ }^{44}$ Creemos que la nueva lectura de las inscripciones en las que aparecen sus hijos, Cayo y Lucio, como patroni confirmaría el patrocinio de Agrippa sobre esta ciudad. Igualmente, no podemos olvidar que la colonia fue fundada por orden de Augusto el 25 a.C. (Dio Cass., 53.26.1), con veteranos procedentes de las guerras cántabras, por lo que no debemos descartar la posibilidad de contemplar un primer patronazgo

40 Gros 1990, 382-389; ID. 2002, 30-34 y 37; MeLChor 2006, 65 y 73-74.

41 Stylow - Ventura 2009, 470, n. 10.

42 Dos epígrafes monumentales colocados sobre los aditi que daban acceso al teatro de Emerita nos indican que M. Agripa ordeno, y por tanto debió financiar, la construcción de este edificio, que fue inaugurado en el 16 a. de C. (CIL II, 474). Junto a éstos existirían otras cuatro inscripciones en el teatro conmemorando su edificación por orden del yerno de Augusto, que fueron estudiadas por J. L. RAMírez SÁDABA 2003, nº 2, 3, 4, 5 y 6, 25-35.

43 El relieve pudo aludir a uno de los ritos de fundación de la ciudad. Cfr. TRILLMICH 1986, 279-304; RoDÀ 2004, 321-322.

44 Roddaz 1993, 120. De la misma forma piensan otros autores, como J. C. SAQuete 1996, 65-66 y 158159 o J. L. RAMírez SÁDABa 2003, 35. 
del Princeps, siempre que nos atengamos a lo establecido en el capítulo 97 de Lex Coloniae Genetivae Iuliae.

El resto de los patronazgos de miembros de la familia imperial que tenemos atestiguados en Hispania (Agripa en Gades; Cayo o Lucio César en Salaria y Ti. Claudius Nero en Italica) vuelven a confirmarnos el interés de las ciudades por vincularse a la domus Augusta. Las fechas en las que se pueden encuadrar estos patrocinios son similares a las ya propuestas para cada uno de los honrados en otras ciudades. En el caso de Gades, Agrippa es mencionado como parens (RPC, 77-80) o como patronus et parens $(R P C, 81-84)$, lo que ha llevado a E. Cardon a proponer que el yerno del Princeps pudo aprovechar su visita a la ciudad, en el 19-18 a.C., para proceder a reorganizar el municipio gaditano, hecho que sería conmemorado con las emisiones monetales que le dan el título de parens. Posteriormente, una vez terminada su misión, el municipio se lo agradecería otorgándole el patronato cívico, acontecimiento que sería inmortalizado mediante la realización de una nueva acuñación monetal. ${ }^{45}$ Es cierto que Gades, en época augustea, pudo recibir su ley municipal definitivamente redactada y que cambió su constitución cuatorviral por otra duunviral, aunque creemos que estos hechos no nos deben permitir hablar de una refundación del municipio que previamente había establecido César en el 49 a.C., cuyas instituciones se encontraban funcionando, al menos, desde el momento en el que Balbo el Menor asumió el cuatuorvirato en Gades. ${ }^{46}$ Por lo señalado, pensamos que el título de parens pudo tener un componente afectivo y de reconocimiento a Agripa como miembro de la gens Iulia (por su matrimonio con la hija de Augusto). Desde ese punto de vista, el yerno del Princeps quedaba conectado familiarmente con el auténtico parens del municipio, el Divus Iulius. Por otra parte, su designación como heredero al trono imperial, tras la muerte de Marcelo en el 23 a.C., justificaría que la ciudad le concediera estos honores y títulos, probablemente en el 19-18 a.C., al igual que explicaría que su retrato apareciera representado en algunas de las mencionadas series monetales ( $R P C, 80,81,83$ y 84). Por todo lo comentado, somos partidarios de mantener una datación temprana para el patrocinio del yerno del Princeps sobre la ciudad (en el 18 a.C.), que sería asumido tras su boda con Iulia (21 a.C.) y coincidiendo con su segunda estancia en Hispania.

45 CARDOn 2004, 47-49. La autora, en la nota 58, de la p. 48, considera que la ausencia de mención, en las emisiones gaditanas que conmemoran el patronato de Agripa sobre Gades, a alguna de las potestades tribunicias que éste comenzó a asumir desde la primera mitad del 18 a.C. no es criterio suficiente para rechazar una datación de estas series -y del patronato- entre el 18 y el 12 a.C., dado que en determinadas emisiones monetales de cecas locales, dedicadas a otros miembros de la casa imperial, este dato pudo omitirse. A. BuRNETT - M. AMANDRY - P. P. RIPOLLÈs 1992, 81, establecen en Gades tres diferentes series monetales que conmemoran a Agripa, proponiendo una datación genérica entre el 27 y el 12 a.C. Por su parte, J. F. RodríGuEZ NeILA 1980, 95, fechó estas emisiones monetales en el 19 a.C.

46 Gades, tras la recepción del estatuto municipal (49 a.C.), tuvo que adaptar sus leyes e instituciones a las normas romanas, en un periodo constituyente que pudo estar culminado mucho antes de la segunda estancia de Agrippa en Hispania; concretamente en el 44-43 a.C., momento en el que el cuestor de la Ulterior de origen gaditano, Balbo el Menor, desempeñó un cuatuorvirato, probablemente quinquenal o de potestad censoria. Balbo, durante el desempeño de la quinquenalidad, debió mandar realizar el primer censo del municipio, así como comicios electorales para elegir a los magistrados. Sobre el tema vid., RodríGuez NeILA 1986, 82-86; ID. $1998,324-327$. 


\section{Sobre el declinar del patrocinio imperial}

Como señaló F. Engesser, en los años inmediatamente anteriores al 2 a.C. Augusto deja de ser mencionado como patrono en la documentación epigráfica, coincidiendo este hecho con la concesión al Princeps, por parte del Senado y a petición del pueblo de Roma, del título de pater patriae (Res Gestae 35.1). Este nuevo título presentaba a Augusto como protector de todos los habitantes del Imperio y haría innecesaria su cooptación como patrono cívico. ${ }^{47}$ La teoría de F. Engesser, generalmente aceptada por los investigadores ${ }^{48}$ puede aplicarse a los diferentes emperadores, incluido Tiberio ${ }^{49}$ pero no a los restantes miembros de la domus imperatoria, ya que ellos, salvo que llegasen a gobernar, no podían ostentar el título de pater patriae. Por tanto, ésta no permite explicar totalmente por qué tras el gobierno de Tiberio no vuelven a aparecer los príncipes como patroni. ${ }^{50}$ Pese a que determinados autores han visto en la desaparición del patronato de miembros de la domus Augusta una prueba de la decadencia del patrocinio cívico senatorial, como institución heredada de época republicana, ${ }^{51}$ nosotros no interpretamos este hecho de la misma forma. El patronato se mantendrá como una vigorosa institución durante el Alto y durante buena parte del Bajo Imperio, aunque transformado y readaptado a las nuevas estructuras del Estado, que impondrán la hegemonía del Princeps sobre el senatus, así como a las estructuras de poder que se implantaron tras la "revolución romana", que permitirán nombrar patroni no sólo a senadores, sino también a miembros de los ordines ecuestre y decurional. Una vez el régimen imperial se consolidó y se crearon nuevos instrumentos de poder, como el culto al emperador o a Roma y Augusto, destinados a exaltar, glorificar y a garantizar la continuidad en el poder de la dinastía gobernante, el patronato cívico debió de perder buena parte de su interés para los miembros de la domus imperatoria. Creemos que el desarrollo del culto municipal al emperador Augusto, en vida de éste, que no sólo está atestiguado en Oriente sino también en diferentes ciudades de Italia o de Hispania, ${ }^{52}$ pudo servir como instrumento, mucho más eficaz

47 ENGESSER 1957, 13-14 y 18-24. Sobre las implicaciones políticas y dinásticas de la adopción, por parte de Augusto, del título de pater patriae vid., SEvery 2003, 158-186. En Hispania, ya en el 6 a.C., cuatro años antes de recibir el título oficialmente, encontramos que el senado de Urgavo Alba dedicó una estatua a Augusto calificándolo de pater patriae $\left(C I L \mathrm{II}^{2} / 7,70\right)$.

48 Nicols 1990, 82-83; CARDON 2004, 53-54.

49 Tiberio fue el único emperador julio-claudio que no asumió el título de pater patriae oficialmente, y por ello lo encontramos como patrono de Aquae Calidae durante su principado (IRC I, 40).

50 Cfr. CARdon 2004, 54. En Hispania, el patronato cívico más tardío de un miembro de la familia imperial, que tenemos atestiguado, es el de Drusus Caesar, hijo de Germánico, en Metellinum (CIL II, 609), que se podría datar entre el 23 y el 29 d.C.

51 Cogitore 1992, 826-829; EILERs 2002, 169-170 y 185-186.

52 Recordemos que en el decreto de honores fúnebres a Cayo César, que aprobó la colonia de Pisae, encontramos ya a un flamen Augustal que se encargaría de entregar el documento al emperador el año 4 d.C. (CIL XI, 1421, líns. 42-43). Incluso, anteriormente, en el 2 d.C., los decuriones de esta colonia se reunieron en el Augusteum para deliberar los honores fúnebres que debían concederse a Lucio César (CIL XI, 1420, lín. 1). Cfr. SegEnNi 2011, 53 y 85-98. Por otra parte, diferentes testimonios literarios y epigráficos nos confirman la existencia, en el ámbito municipal, de un culto al emperador y de un sacerdocio específico para tal fin en vida del propio Augusto. En referencia a Hispania, debemos destacar una conocida anécdota narrada por Quintiliano (Inst. Orat. VI 3.77), quien señala que, cuando los tarraconenses comunicaron al Princeps el 
que el patrocinio, para garantizarse la lealtad y fidelidad de numerosas comunidades cívicas; y al ser complementado con una tutela general sobre todos los habitantes del orbe romano, que se pone de manifiesto en la concesión a Augusto del título de pater patriae, pudo hacer innecesario mantener unas relaciones de patronazgo municipal que, tras ser adaptadas al nuevo régimen, fueron dejadas en manos de miembros de los tres ordines privilegiados de la sociedad romana, con los que el Princeps contó, desde un primer momento, para gobernar el Imperio.

Por otra parte, durante el gobierno de Augusto el patronato municipal perdió buena parte del valor político que tuvo en época republicana, como hipotético proveedor de votantes en las elecciones o de soldados para los ejércitos, ${ }^{53}$ y quedó asimilado a un honos otorgado por las ciudades a sus protectores y benefactores. ${ }^{54}$ Los patroni cívicos pasarán a ser vistos ya no como posibles competidores, sino como colaboradores del régimen imperial. ${ }^{55} \mathrm{El}$ patrono municipal de época imperial será elegido, fundamentalmente, en función de su capacidad de ejercer influencia o de mediar ante el Princeps y ante su administración; por tanto, su poder y prestigio no derivará ya

milagro de la palmera crecida sobre un ara dedicada a él, Augusto lo atribuyó a su poco uso. Igualmente, diferentes epígrafes nos confirman la existencia, en vida de Augusto, de flámines (CIL II²/7, 144 de Epora) o pontífices creados para dar culto al emperador (CILA II, 382 y 383, procedentes del teatro de Italica $=$ GonZÁLEZ 1991-96), así como de algún edificio sacro consagrado a dicho culto (CIL II²/7, 253 de Corduba). Otros testimonios hispanos de monumentos votivos dedicados al Princeps, estando vivo el emperador, fueron recogidos por J. GonZÁLEZ 2007, 179-184 (CIL II, 2703 y 5182; ILER 1028). Sobre la datación augustea, tanto del teatro como de las inscripciones de Italica que mencionan a los pontific(es) prim [i cr]eati Augusto (CILA II, 382 y 383), quienes contribuyeron a financiar la construcción del edificio, vid., RoDRíGUEZ GuTIÉRREZ 2004, 287-293 y $552-556$.

53 Recientemente, F. PINA Polo 2012, 55-79, se ha mostrado partidario, creemos que muy acertadamente, de redimensionar el fenómeno, replanteando a la baja el número de posibles clientes de grandes familias senatoriales que pudo haber en provincias y limitando la importancia del patronato en la vida política de la urbs o en las guerras civiles de fines de la República.

54 El título de patrono se utilizó como un honor que permitía darles las gracias por los servicios prestados o por los beneficios concedidos a las ciudades tuteladas. Cfr. Veyne 1976, 349, n. 219 y 767, n. 311; Seguí 1988, 164.

55 El Princeps había concebido un imperio que tenía como base organizativa numerosas ciudades, que ya contaban con un importante cuerpo de ciudadanos romanos. En esas poblaciones era conveniente mantener, al igual que en Roma, un "confortable" nivel de vida que garantizase el consenso social y la tranquilidad de la población. Para lograr estos objetivos, Augusto contó con la ayuda e implicación de los miembros de los tres ordines privilegiados de la sociedad romana, grupos sociales de los que salieron la casi absoluta mayoría de los patroni conocidos. Senatores, equites y decuriones, a cambio de mantener una destacada posición social, política y económica dentro de las estructuras del nuevo Estado, tuvieron que asumir una serie de funciones que en Roma eran realizadas por el emperador. Nos referimos a la inversión de parte de su riqueza, mediante la realización de actos evergéticos, en el bienestar de la plebe, ayudando de esta forma a costear parte de los servicios que los municipios ofrecían a sus administrados (Melchor 1999, 19 y 67). Aunque no creemos que los patronos cívicos desempeñasen una actividad superior a la del resto de las élites del Imperio (decurionales, ecuestres o senatoriales) en la financiación de programas de urbanización y monumentalización de las ciudades o en la organización de espectáculos y distribuciones (banquetes, repartos de dinero, comida y aceite, etc.) que hicieran más agradable la vida urbana, éstos, al tener vínculos patronales con determinadas comunidades cívicas, también participaron en el desarrollo del sistema evergético que se implantó en todas las ciudades del Imperio romano, contribuyendo a fomentar la paz y la concordia ordinum que tanto propugnaba el régimen augusteo. Bajo esta óptica, el patronazgo cívico favoreció que personajes de alto rango, imitando la conducta y las actuaciones del Princeps en la Urbs, pudieran fijar su atención y conceder diferentes tipos de beneficia (materiales, de gestión, etc.) a ciudades que en ocasiones se encontraban muy distantes de Roma o de sus lugares de residencia, en las que habían sido cooptados como patroni. 
de tener una extensa clientela o de su independencia, sino de su lealtad, vinculación y subordinación a la domus imperatoria. De lo comentado debemos deducir que el patronazgo municipal fue "domesticado" y puesto al servicio del Princeps, quien aparecerá ante el pueblo como pater patriae y como fuente de la que emana el poder, ante el que los patroni municipales intentarán interceder en beneficio de las colectividades cívicas a las que tutelaban. ${ }^{56}$ Desde este punto de vista, la institución quedó subordinada al poder del Princeps, haciendo totalmente innecesario, y probablemente inapropiado, que el emperador o los príncipes continuaran asumiendo el patronato cívico.

\section{El patrocinio cívico de miembros de la casa imperial en época de Tiberio}

Como últimas muestras de testimonios del patronazgo cívico asumido por miembros de la familia imperial, encontramos que Tiberius Caesar Augustus, único emperador julio-claudio que no asumió el título de pater patriae oficialmente, fue patrono de Aquae Calidae durante su principado (IRC I, 40), mientras que Drusus Caesar lo fue de Metellinum (CIL II, 609).

Sobre el epígrafe en el que figura Tiberio existen diferentes interpretaciones. G. Fabre, M. Mayer e I. Rodà plantearon que el texto pudo pertenecer a una inscripción monumental y que éste iría en nominativo, sobre un friso, conmemorando la construcción de un pórtico o de otro edificio público mandado levantar por disposición de Tiberio. No obstante, tampoco descartaron que el texto pudiese ir en dativo y que se tratase de un titulus de carácter honorífico dedicado al emperador como patrono de la comunidad cívica, opción que finalmente aceptaron, al aparecer una tercera línea del epígrafe ${ }^{57}$ Frente a esta lectura, E. Cardon considera que el texto originariamente estaría distribuido en dos líneas, pertenecería a una inscripción monumental e iría en nominativo, por lo que aludiría a la realización de una construcción pública. ${ }^{58} \mathrm{Desco}-$ nocemos en qué momento Tiberio aceptó el patrocinio sobre Aquae Calidae. Aunque por su titulación como Tiberio César Augusto la inscripción debe datarse entre el 14 y el 37 d.C., creemos que no debe descartarse la posibilidad de que su cooptación como patrono hubiera tenido lugar en un momento anterior a su acceso al poder.

56 Las ciudades ya no buscarán, como en época republicana, a patroni que introdujeran a sus embajadas y defendieran sus causas ante el Senado de Roma (Cfr. Bell. Hisp. 42.2), sino que los representasen ante el emperador. Como señaló M. Cornelio Frontón a sus conciudadanos de Cirta (a mediados del siglo II d.C.) y como parece deducirse del perfil de los candidatos que él recomienda a su ciudad, debían buscarse patronos cívicos con influencia en Roma, que hubieran desempeñado en la Urbs las magistraturas superiores o que mantuviesen relaciones directas con el emperador (ad am. 2, 11). Este modelo de patrono fue válido ya desde inicios del Principado.

57 IRC I, 40, p. 86 e IRC V, p. 19 (=FABRE - MAYER - Rodì 2002, 19): Ti(berio) Caesa[ri Divi]/[Au]g(usti) f(ilio) [Augusto o Aug(usto)]/ [P]atr[ono].

58 CARDON 2004, 52-53. La investigadora cree que la altura de las letras del epígrafe no permite identificar el soporte con un pedestal destinado a celebrar el patrocinio de Tiberio sobre la ciudad y retoma una propuesta ya planteada en IRC I, 40, aunque modifica la lectura del titulus: Ti(berius) Caesa[r Divi Au]g(usti) f(ilius) [Divi Iuli n(epos) Augustus P]atr[onus]. 
El listado de patroni cívicos pertenecientes a la familia imperial se cerrará con Drusus Caesar, hijo de Germánico y Agripina, quien debió ser cooptado patrono de Metellinum entre el 23 d.C., fecha de su nombramiento como heredero imperial, y el 29 d.C., momento de su caída en desgracia, tras ser acusado de conspirar contra Tiberio. En esta colonia cesariana, tanto las dedicaciones honoríficas a Cayo César (CIL II, 607) y a Germánico (ILER 1053), como el patrocinio de Druso, parecen indicar que las relaciones clientelares con la familia imperial pudieron ser más antiguas y provenir de lazos previamente establecidos con el mismo Princeps, como ya hemos defendido que ocurrió en otras comunidades cívicas hispanas (Emporiae, Ulia, Carthago Nova o Augusta Emerita). Desde este momento, las fuentes no mencionan a ningún otro patrono cívico perteneciente a la domus imperatoria en todo el Imperio, pues el testimonio atribuido al emperador Nerva por L. Harmand ${ }^{59}(A E 1927,43)$ no pertenece a él, sino a un ancestro suyo. ${ }^{60}$

\section{Epílogo}

Como hemos intentado mostrar, el patronazgo cívico fue integrado dentro del sistema político establecido por Augusto y subordinado al poder imperial, ya que una de las principales funciones de los patroni fue la de representar y defender los intereses de sus ciudades clientes ante el emperador o ante la administración, misión que se podía desempeñar de forma más efectiva si se era un leal colaborador del Princeps. A partir de este momento, las exigencias para ser patrono debieron de relajarse, tras comprobarse que esta institución no hacía peligrar ni discutía la autoridad imperial. Así parece ponerlo de manifiesto el mencionado capítulo 61 de la Lex Irnitana (vid. supra y fig. 1) y la ausencia, al menos en la parte conservada de esta ley, de cualquier norma específica destinada a dificultar el nombramiento de patroni de rango senatorial mediante el aumento del número de sufragios afirmativos necesarios para su cooptación.

Pese a lo señalado, y pese a la desaparición del patronazgo imperial, las ciudades y la administración central continuaron dando gran importancia al patrocinio sobre las comunidades cívicas, ya que éste es el único honor cuya concesión aparece regulada en las leyes municipales flavias. Igualmente, la documentación epigráfica conservada sobre patronos municipales muestra que esta institución, puesta al servicio del bien común, se mantuvo con gran vitalidad durante el Alto y el Bajo Imperio, ${ }^{61}$ siendo muy valorada por las ciudades, que cooptaron a numerosos patroni, y por los miembros de los tres ordines privilegiados de la sociedad romana, que continuaron asumiendo el patronazgo en numerosas comunidades cívicas.

59 HaRmand 1957, 165.

60 Como puede verse en $P I R^{2} \mathrm{C}, \mathrm{n}^{\circ} 1224$.

61 Ver, al respecto, los listados de patroni publicados por L. HARmand 1957, 188-284; R. Duthoy $1984-$ 86, 136-154 y J. Nicols 2014, Web Site: https://scholarsbank.uoregon.edu/xmlui/handle/1794/13015. 


\section{BibLIOGRAFÍA}

ABASCAL, J. M.

(1996): "Programas epigráficos augusteos en Hispania", AAC 7, 45-82.

(2002): "La fecha de la promoción colonial de Carthago Nova y sus repercusiones edilicias", Mastia 1, 21-44.

(2006): "Los tres viajes de Augusto a Hispania y su relación con la promoción jurídica de ciudades", Iberia 9, 63-78.

Abascal J. M. - Ramallo, S. (1997): La ciudad de Carthago Nova: la documentación epigráfica, Murcia.

Amela Valverde, L. (2009): Hispania y el segundo triunvirato (44-30 a.C.), Madrid.

Beltrán, F. - Pina, F. (2013): “Clientela y patronos en Hispania”, [en] J. López Vilar (ed.), Tarraco Biennal. Actes 1er Congrés Internacional d'Arqueologia i Món Antic. Govern i societat a la Hispània romana. Novetats epigràfiques. Homenatge a Géza Alföldy, Tarragona, 51-61.

BLOY, D. (2012) "Roman patrons of Greek communities before the title $\pi \alpha ́ \tau \rho \omega v "$, Historia $61 / 2,168-201$.

Bonneville, J. N. (1986): "Les patrons du municipe d'Emporiae”, REA 88, 181-200.

Burnett, A. - Amandry, M. - Ripollès, P. P. (1992): Roman Provincial Coinage. Vol. I: From the death of Caesar to the death of Vitellius (44 BC-AD 69), London-Paris.

CABallos Rufino, A. (2006): El nuevo bronce de Osuna y la politica colonizadora romana, Sevilla.

CANAli De Rossi, F. (2001): Il ruolo dei patroni nelle relazioni politiche fra il mondo greco e Roma in età Repubblicana ed Augustea, Leipzig.

CAnto, A. Ma

(1989): “Colonia Iulia Augusta Emerita: consideraciones en torno a su fundación y territorio", Gerión 7, 149-205.

(1990): "Las tres fundaciones de Augusta Emerita", en Stadtbild und Ideologie. Die Monumentalisierung hispanischer Städte zwischen Republik und Kaiserzeit, Madrid, 1987, München, 289-297.

CARDOn, E. (2004): "Le patronat municipal en Bétique et en Tarraconaise sous les premiers Julio-Claudiens. Un exemple de loyalisme dynastique", [en] J.-M. André (ed.), Hispanité et romanité, Madrid, 39-58.

Centrini, G. (2010): “Gaio e Lucio Cesari, nipoti e successori di Augusto: la documentazione occidentale", RSA 40, 109-135.

Chausson, F. (2004): "Les patronats familiaux en Afrique et en Italie aux IV $-V^{\mathrm{e}}$ siècles: un dossier épigraphique”, Rend. Mor. Acc. Lincei, s. 9, v. 15, 71-120.

CoGitore, I. (1992): "Séries des dédicaces italiennes à la dynastie julio-claudienne", MEFRA 104/2, 817-870.

CraWford, M. H. (ed.), (1996): Roman statutes, 2 vols, London.

DíAz Ariño, B.

(2008a): "Las murallas romanas de Cartagena en la segunda mitad del siglo I A.E.", Zephyrus 61, 225-234.

(2008b): "Un quaestor pro praetore republicano en Carthago Nova", JRA 21/1, 255-263. 
D'Ors, X. (1997): “Observaciones formales sobre la composición de la Lex Ursonensis", Stvd. Hist., $H^{a}$ Antig. 15, 1997.

Duthoy, R. (1984-86): “Le profil social des patrons municipaux en Italie sous le Haut-Empire", Ancient Society 15-17, 121-154.

EILERS, C. (2002): Roman patrons of Greek cities, Oxford.

ENGESSER, F. (1957): Der Stadtpatronat in Italien und den Westprovinzen des Römischen Reiches bis Diokletian, Freiburg.

FABre, G. - MAYER, M. - RoDÀ, I.

(1984): Inscriptions Romains de Catalogne I, Barcelone, Paris.

(1991): Inscriptions Romains de Catalogne III, Gerona, Paris.

(2002): Inscriptions romaines de Catalogne V, Paris.

FAsolini, D. (2012): Le tribù romane della Hispania Tarraconensis. L'ascrizione tribale dei cittadini romani nelle testimonianze epigrafiche, Milano.

GoNZÁLEZ, J.

(1991-96): Corpus de Inscripciones Latinas de Andalucía, Vol. II, Sevilla, IV vols., Sevilla. (2007): “El origen del Culto Imperial en la Bética según la documentación epigráfica", [en] T. Nogales - J. González (eds.), Culto Imperial: política y poder, Roma, 173-189.

Gros, P.

(1990): "Théâtre et culte impérial en Gaule Narbonnaise et dans la Péninsule Ibérique", [en] Stadtbild und Ideologie. Die Monumentalisierung hispanischer Städte zwischen Republik und Kaiserzeit, Madrid, 1987, München, 381-391.

(2002): "La fonction politique des monuments du spectacle dans le monde romain sous le Haut-Empire", [en] Ludi romani. Espectáculos en Hispania romana, Mérida, 25-40.

HaRmand, L. (1957): Le patronat sur les collectivités publiques des origines au Bas-Empire, Paris.

Hurlet, F. (1997): Les collègues du Prince sous Auguste et Tibère, Paris-Roma.

Косн, М. (1979): “M. Agrippa und Neukarthago", Chiron 9, 205-214.

Lintott, A. (1999): Imperium Romanum. Politics and administration, London-New York.

Llorens Forcada, M. M. (1994): La ciudad de Carthago Nova: las emisiones monetales, Murcia.

Melchor Gil, E.

(1999): La munificencia cívica en el mundo romano, Madrid.

(2006): "Teatro y evergetismo en la Hispania romana", [en] C. Márquez - A. Ventura (coords.), Jornadas sobre teatros romanos en Hispania, Córdoba 2002, Córdoba, 57-80. (2013): "Formas de ingreso de nuevos decuriones en los senados municipales", [en] E. Melchor Gil - A. D. Pérez Zurita - J. F. Rodríguez Neila (eds.), Senados municipales y decuriones en el Occidente romano, Sevilla, 215-236.

NicOLS, J.

(1978): "The emperor and the selection of the patronus civitatis. Two examples", Chiron 8 , 429-432.

(1979): "Zur Verleihung öffentlicher Ehrungen in der römischen Welt", Chiron 9, 243-260.

(1990): "Patrons of greek cities in the Early Principate", ZPE 80, 81-100.

(2014): Civic patronage in the Roman Empire, Leiden-Boston. 
Pina Polo, F.

(2008): "Hispania of Caesar and Pompey. A conflict of clientelae?", [en] M. P. GarcíaBellido et alii (eds.), Del imperium de Pompeyo a la auctoritas de Augusto. Homenaje a Michael Grant, Anejos de AEspA 47, Madrid, 41-48.

(2012): “Generales y clientelas provinciales: ¿qué clientelas?”, [en] J. Santos Yanguas - G. Cruz Andreotti (eds.), Romanización, fronteras y etnias en la Roma antigua: el caso hispano, Vitoria, 55-79.

Ramallo, S. - Murcia, A. J. (2010): “Aqua et lacus en Carthago Nova. Aportaciones al estudio del aprovisionamiento hídrico en época romana", ZPE 172, 249-258.

Ramallo, S. - Ruiz, E. (1998): El teatro romano de Cartagena, Murcia.

RAmíRez SÁDABA, J. L. (2003): Catálogo de las inscripciones imperiales de Augusta Emerita, Mérida.

RAMPAZzo, N. (2007): "La cooptatio nel patronato civico e nella costituzione dei senati periferici”, en] E. Lo Cascio - G. D. Merola (cur.), Forme di aggregazione nel mondo romano, Bari, 191-208.

RodÀ, I. (2004): “La figura de Agripa en Hispania”, [en] C. Pérez-González - E. Illarregui (coords.), Arqueología militar romana en Europa, Salamanca, 319-331.

RodDAZ, J.-M.

(1984): Marcus Agrippa, Roma.

(1993): “Agripa y la Península Ibérica”, Anas 6, 111-126.

RoDríguez GutiÉRrez, O. (2004): El teatro romano de Itálica. Estudio arqueoarquitectónico, Madrid.

Rodríguez NeILA, J. F.

(1980): El municipio romano de Gades, Cádiz.

(1986): "Cuestiones en torno a la censura municipal romana”, Gerión 4, 61-99.

(1988): "Sobre la fase constituyente de las entidades municipales romanas (con particular referencia a la Bética)", [en] J. Mangas - J. Alvar (eds.), Homenaje a José Ma Blázquez, vol. V, Madrid, 313-334.

Saquete, J. C. (1996): Las élites sociales de Augusta Emerita, Mérida.

SEGENNI, S.

(2009): "Patroni e tabulae patronatus nella regio IV', Studi Classici e Orientali 55, 261282.

(2011): I Decreta Pisana. Autonomia cittadina e ideologia imperiale nella colonia Opsequens Iulia Pisana, Bari.

Seguí Marco, J. J.

(1988): Patronato y patronos públicos en Hispania durante el Alto Imperio, Valencia (Tesis doctoral en microfichas).

(1996): "Un aspecto particular en las relaciones hispano-africanas durante el Alto Imperio: los patrocinios públicos", [en] L'Africa Romana. Atti del XI Convegno di Studio, Cartagine, 1994, Ozieri, 1547-1564.

SEVERY, B. (2003): Augustus and the family at the birth of the roman empire, London-New York.

SPADONI, M. C. (2004): I prefetti nell'amministrazione municipale dell'Italia romana, Bari. 
STYlow, A. U.

(1997): “Apuntes sobre la arqueología de la Lex Ursonensis", Stvd. Hist., H ${ }^{a}$ Antig. 15, 35-45. (2008): "Ein neuer Statthalter der Baetica und frühe Reiterstatuenpostamente in Hispanien", [en] M. L. Calderini et alii (cur.), Epigrafia 2006, Atti della XIVe rencontre sur l'épigraphie in onore di Silvio Panciera con altri contributi di colleghi, allievi e colaboratori, Roma, 1051-1062.

Stylow, A. U. - Ventura, A. (2009): "Los hallazgos epigráficos", [en] R. Ayerbe et alii (eds.), El foro de Augusta Emerita. Génesis y evolución de sus recintos monumentales, Anejos de AEspA 53, Mérida, 453-523.

Syme, R. (1989): La revolución romana, Madrid.

Trillmich, W. (1986): "Ein historisches Relief in Mérida mit Darstellung des M. Agrippa beim Opfer", Madrider Mitteilungen 27, 279-304.

Veyne, P. (1976): Le pain et le cirque. Sociologie historique d'un pluralisme politique, Paris.

ZANKer, P. (1992): Augusto y el poder de las imágenes, Madrid. 